\title{
Will the US clone alone?
}

The publication two weeks ago of the initial sequencing and analysis of the human genome will forever change the way we study, diagnose and prescribe medicine. The excitement surrounding the release of the sequence has led to an obsession with the genetic basis of who we are and the diseases to which we are susceptible. This interest in our genetic identity intensified as researchers also announced that they were ready to start trying to clone humans. Although there is currently a ban in the United States on the use of federal funds for human cloning research, there are no restrictions on the use of private money for this purpose. With human genetics research in the public spotlight, it is an opportune time for the US government to take a close look at where human cloning research is going in the near future, and to devise a way to regulate it.

The first mammal was cloned in 1997 by Scottish scientists at the Roslin Institute who used somatic cell nuclear transfer to create Dolly the sheep. Hundreds of other animals have since been cloned, including cows, pigs and mice. Last month, Panos Zavos of the University of Kentucky, Lexington, and Italian fertility specialist Severino Antinori incited uproar by announcing that they would begin a collaborative effort to clone a human within the next two years. Although the team promised to attempt human reproductive cloning only to aide people with no other means of having genetically-related children, the announcement sparked a debate over the social and ethical implications of creating human clones.

Within days of the published report of Dolly, President Clinton signed a five-year moratorium on the use of federal funds for human cloning research. In June of 1997 , the National Bioethics Commission recommended that federal legislation be enacted to prohibit anyone, whether in a research or clinical setting, from attempt- ing to create a child through somatic cell nuclear transfer. In July of the same year, the Clinton administration submitted the 'Cloning Prohibition Act of 1997', which proposed to prohibit the creation of human beings using somatic cell nuclear transfer technology. However, this legislation has been tied up in Congress, making human reproductive cloning still legal in the US with private funds.

Zavos and Antinori are not alone, as other groups have entered the race. Although cloning the first human would be an amazing technical feat, we must consider the long-term outcomes of having this technology up and running. Will a large number of companies spring up, offering to clone anyone for a price? If so, these companies are likely to prey upon grieving people who have not accepted the loss of a friend or relative, and will pay any price to have them 'replaced'. Such companies are not likely to explain to clients that they won't get their loved one back-just another person that carries the same DNA and resembles the original.

In addition to ethical concerns, much of the debate surrounding human cloning is based on technical and safety issues. Cloned cattle and sheep are frequently oversized at birth, possess a variety of birth defects and have exceptionally high rates of fetal and neonatal mortality. Cloned mice were reported to have a longer life span, suggesting the presence of physiological alterations. The longterm effects in humans may include an increased predisposition to a variety of diseases, including cancer.

Luckily, we are likely to be a few years off from meeting the first cloned person, as cloned animals that develop into healthy adults are the exception rather than the rule. Over $95 \%$ of cloned embryonic mice die before implantation or in utero and after implantation. Scientists at the Roslin Institute made 272 unsuccessful attempts before creating Dolly. Producing one single human clone would necessitate a large number of miscarriages, stillbirths or infants born with birth defects.

While there are many dangers to cloning, this technology holds great promise for medical research. Human therapeutic cloning involves the transfer of a patient's somatic cell nuclei into enucleated oocytes, development of the embryo to the morula or blastocyst stage, and isolation of stem cells that can differentate into immunologically-matched tissues. For example, somatic cell nuclear transfer may someday be used to grow neurons for Parkinson or Alzheimer disease patients, islets for diabetics or bone marrow cells for cancer patients-all while avoiding the threat of graft rejection.

It is bewildering that a country obsessed with the sanctity of the human embryo has left this form of reproduction essentially unregulated. Human cloning for any purpose-reproductive or therapeutic-is illegal in Japan. In the United Kingdom, a government-appointed panel recently recommended that scientists should be permitted to create cloned embryos by nuclear transfer for research purposes only, and that these embryos cannot be maintained for longer than 14 days.

Instead of making it a priority to restrict embryonic stem cell research (which he has hinted that he will do), President Bush should first take the advice of the National Bioethics Commission and urge Congress to prohibit research aimed at creating a human being using cloning technology. Research involving somatic cell nuclear transfer for therapeutic purposes, however, should continue to be permitted. Of course there are many other countries without any laws whatsoever regarding human cloning, where cloners could move and set up shop. The US should set an example for these countries and put this research on hold untll we can better understand its risks, as well the potential ethical and social outcomes. 